\title{
Martín de Riquer, cervantista
}

\author{
CARlos Alvar*
}

Cumple en 2014 el centenario del nacimiento de Martín de Riquer, apenas un año después de su desaparición. Se juntan, pues, dos ocasiones para rememorar la figura del que fue uno de los más destacados cervantistas del siglo XX. Sus trabajos han servido como iniciación en la lectura del Quijote, como aclaración sistemática de episodios, y como explicación aguda de figuras y armas de la obra de Cervantes. Se trata de tres niveles distintos en los que quedaría de manifiesto un hecho fundamental: el interés de Riquer por facilitar el camino al lector mediante un didactismo alejado de cualquier pedantería, y no por eso menos erudito, menos filológico.

Desde 1942, Riquer enseñaba Literatura española en la Universidad de Barcelona. Con frecuencia se olvida esta vertiente de hispanista, buen conocedor de nuestra Edad Media y del Siglo de Oro. Es necesario recordar que del año 1943 es su edición del Tesoro de Sebastián de Covarrubias, la antología de la prosa de fray Antonio de Guevara, un artículo sobre Petrarca y la Crónica sarracina de Pedro del Corral, una nota al Quijote, y del año siguiente es su primera edición de la novela de Cervantes ${ }^{1}$; luego vendrán Calderón y Camoens, Fray Luis de León, el Arcipreste de Talavera, Juan de Mena, el Cid... ${ }^{2}$. Todo ello, antes de 1950, y alternando con trabajos sobre literatura catalana y provenzal. El Cavallero Zifar, Francisco de Luque Fajardo o Don

* Instituto de investigación «Miguel de Cervantes» y Universidad de Alcalá.

1. Sebastián de Covarrubias, Tesoro de la lengua castellana o española. Barcelona: Imprenta Horta; Antonio de Guevara, Prosa escogida. Prólogo y selección. Barcelona: Miracle; «El Africa de Petrarca y la Crónica sarracina de Pedro del Corral», Revista de Bibliografía Nacional, IV: 293-295; «'Echar a galeras’ y el pasaje más oscuro del Quijote», Revista de Filología Española, XXVII: 82-86; Miguel de Cervantes (1944), Don Quijote de la Mancha, edición y notas. 3 vols. Barcelona: Juventud.

2. La enumeración no es, ni mucho menos, exhaustiva. Calderón de la Barca (1945), La vida es sueño. Barcelona: Juventud; Luis de Camoens (1945), Poesía castellana y fragmentos de "Los Lusíadas" según la versión de Enrique Garcés (1591). Barcelona: Montaner y Simón; (1946), «Dos manuscritos con poesías de fray Luis de León», Analecta Sacra Tarraconensia, XIX: 241-261; Alfonso Martínez de Toledo, Arcipreste de Talavera (1949), Corbacho o reprovación del amor mundano. Barcelona: Selecciones Bibliófilas; Juan de Mena (1949), La Ylíada en romance según la impresión de Arnao Guillén de Brocar (Valladolid, 1519). Barcelona: Selecciones Bibliófilas; (1949), «jDios, qué buen vassallo, si oviesse buen señor!», Revista Bibliográfica y Documental, III: 257-260. 
Juan Manuel, Triste deleytación, Juan Boscán, Fernando de Rojas, y un larguísimo etcétera atestiguan su dedicación al medievalismo en unos casos o al hispanismo y en especial al Siglo de $\mathrm{Oro}^{3}$. Las obras de muchos de los autores citados no habían sido objeto de una edición moderna, y Riquer facilitó el acceso de esos textos a los estudiosos y a los estudiantes.

La edición del Quijote se convirtió en un modelo de anotación sucinta, esencial, que no interfería en la lectura y que facilitaba enormemente la comprensión del texto: fue ésa una de las razones que hizo que su edición se haya mantenido en el mercado de forma ininterrumpida desde 1944 hasta nuestros días; es decir, más de setenta años sin perder vigencia, y tanto en ediciones populares, como en lujosos volúmenes «de artista».

Y por si eso fuera poco, en 1958 publicó por primera vez su Introducción a la lectura del Quijote, que luego fue reeditada en numerosas ocasiones y en varias editoriales ${ }^{4}$. En esta obra, Riquer explicaba los orígenes de los libros de caballerías haciendo una útil presentación de la materia de Bretaña y de su llegada a España a través del Amadís de Gaula y del influjo que tuvo la vida caballeresca de la ficción en la realidad del siglo XV y comienzos del siglo XVI, aspecto que tendría un cumplido desarrollo posterior en el discurso de ingreso de nuestro cervantista en la Real Academia Española (1965) ${ }^{5}$. La vida y obra de Cervantes, con sus numerosos viajes -incluido el de Barcelona- constituye otro de los elementos esenciales de este accessus ad auctorem, que nos lleva a continuación al Quijote y al entorno ideológico en el que aparece, cuando las críticas de moralistas y hombres graves censuran estas ficciones disparatadas. Y poco a poco, casi sin que nos demos cuenta, nos encontramos dentro de la novela de Cervantes, pues hay un continuum que lleva de la percepción de la obra, al interior de la misma. El resto podría ser previsible: un ameno resumen de la novela; y sin embargo, Riquer no pierde la ocasión de ir señalando los aspectos más relevantes de cada episodio, de tal forma que el libro es, a la vez, una «introducción» y una guía crítica, en la que el autor va advirtiendo de los posibles errores en la lectura, de las claves de interpretación de las situaciones, o de los paralelismos con otras

3. (1953), El cavallero Zifar, con un estudio. 2 vols. Barcelona: Selecciones Bibliófilas; Francisco de Luque Faxardo (1955), Fiel desengaño contra la ociosidad y los juegos. 2 vols. Madrid: Real Academia Española; (1955), Obras de don Juan Mnuel, en colab. con José Ma Castro y Calvo. Vol. I. Barcelona: CSIC; (1956), «Triste deleytación, novela castellana del siglo XV», Revista de Filología Española, XL: 33-65; (1957), Obras poéticas de Juan Boscán. Edic. crítica en colab. con Antoni Comas y Joaquim Molas. Barcelona: Facultad de Filosofía y Letras; (1957), «Fernando de Rojas y el primer acto de La Celestina», Revista de Filología Española, XLI: 373-395; Fernando de Rojas (1959), “La Celestina” y "Lazarillos”, el primero y el de Juan de Luna. Barcelona: Vergara.

4. Formaba parte de la edición del Quijote de la editorial Labor de Barcelona. Después sería publicada de forma exenta con el título de Aproximación al Quijote por Teide, Barcelona, 1977, con cuatro reediciones hasta 1986, y por Salvat, Barcelona, 1970 (con prólogo de Dámaso Alonso, reimpresa dos veces). La Editorial Teide publicó una versión ampliada, con el título de Nueva aproximación al Quijote, en 1989.

5. (1965). Vida caballeresca en la España del siglo $X V$, con contestación de Dámaso Alonso. Madrid: RAE. 
obras. El provecho es evidente, pero, además, contamos con la apasionada y apasionante lectura que hace Riquer de la novela cervantina.

En la larga bibliografía de nuestro maestro no faltaron otros acercamientos más específicos aún al conjunto de la obra de Cervantes en general, o al Quijote, en particular. En todo caso, esos estudios dieron lugar a dos bellas colecciones de artículos: una, dedicada a Cervantes, Passamonte y Avellane$\mathrm{da}^{6}$; la otra, a Cervantes en Barcelona ${ }^{7}$. En la primera retoma la hipótesis, ya planteada en 1969, de que el autor del Quijote apócrifo que se encubría bajo el pseudónimo de Fernández de Avellaneda no era otro que el aragonés Gerónimo de Passamonte, autor de su autobiografía: para reforzar ahora esta teoría, Riquer escudriña con detalle la vida del personaje histórico, su relación con Cervantes en los tiempos de la milicia, en el cautiverio y después del regreso a España. A continuación, establece la identidad de Ginés y Gerónimo, y de éste con Avellaneda. La abundancia de detalles procedentes de los Quijotes sirven para establecer un diálogo del que poco a poco van saliendo nuevas conclusiones, apoyadas en datos históricos: un trabajo positivista, de investigador minucioso y atento, en el que se puede apreciar la emoción del estudioso por sus hallazgos y la satisfacción de los resultados alcanzados; y aún volverá sobre el tema para rematar algún fleco suelto, como la identificación propuesta de Parapil la que no sería sino una denominación insultante y vejatoria del propio Passamonte.

Aparentemente distinto es el método seguido en el volumen dedicado a Barcelona, que da cabida a estudios variados, en los que de nuevo asoma el positivismo de pequeños detalles concretos, con resultados de amplio alcance: fechas, hechos, identificaciones de personajes y episodios sitúan a Cervantes en la Ciudad Condal en el verano de 1610; otros detalles hacen pensar que nuestro autor sitúa la acción del Quijote en el verano de 1614; luego, Riquer llegará a la conclusión de que Rocaguinarda, el bandolero, no es otro que Roque Guinart. Sin duda, la estancia barcelonesa de 1610 le suministró abundante información para redactar algunos episodios de la novela y de «Las dos doncellas», aunque no siempre la verosimilitud del relato coincida con la historicidad. Todos ellos son temas que habían llamado la atención a Riquer desde sus primeros acercamientos al apócrifo de Avellaneda y al conjunto de la obra cervantina en los años sesenta.

Aún aplicará Riquer sus conocimientos para hablar de las armas en el Quijote, cerrando un ciclo dedicado al armamento y que había empezado en 1968 con L'arnès del cavaller ${ }^{8}$; seguido por los estudios sobre el armamento en la Historia Troyana ${ }^{9}$, en el Victorial ${ }^{10}$, y especificaciones

6. Barcelona: Sirmio, 1988.

7. Barcelona: Sirmio, 1989.

8. Vio la luz en la editorial Ariel, Esplugues de Llobregat (Barcelona).

9. (1969), "El armamento en el Roman de Troie y en la Historia Troyana", Boletín de la RAE, 49: $463-494$.

10. (1983), "Las armas en el Victorial", en Serta Philologica F. Lázaro Carreter. Madrid: Cátedra, pp. 159-177. 
sobre aspectos más concretos, como la «loriga» o las «armas de tota boça» ${ }^{11}$.

En fin, el deseo de Riquer de llegar a un público amplio le llevó a recoger una gran parte de su producción cervantina en el año 2003, en una guía para leer a Cervantes, centrada en la novela, y en la que retoma temas ya esbozados, o desarrollados desde cuarenta años antes ${ }^{12}$. Es un libro en el que quedan de manifiesto los conocimientos del autor, su método, su sensibilidad de filólogo y una magnífica intuición para plantear soluciones donde antes habían tropezado los cervantistas, para aclarar aspectos poco tratados y para transmitirnos su alegría por el estudio y los resultados siempre brillantes del mismo: si llegaba el caso - aceptaba- de que alguien consiguiera demostrar que se había equivocado en alguno de sus planteamientos, al menos quedaría siempre el trabajo hecho, que podía servir a los demás. Todo un ejemplo de honestidad científica, acompañada de un fino y sutil sentido del humor.

Con Riquer ha desaparecido el último gran cervantista del siglo XX.

11. (1978), "Le haubert francès y la loriga castellana", en Mélanges de Philologie et de littératures romanes offerts à Jeanne Wathelet-Willem. Marche Romane (Liège), pp. 545-568; (1979), "Armes de tota boça i armes de mija boça", en Homenatge a Francesc de B. Moll, I, Randa, 9: 63-64.

12. (2003), Para leer a Cervantes. Barcelona: Acantilado. 